\title{
Origin of anterior descending branch of left coronary artery from pulmonary trunk
}

\author{
P. Probst, O. Pachinger, H. Koller, M. Niederberger, and F. Kaindl \\ From the Cardiological Clinic of the University of Vienna, Vienna, Austria
}

Several cases of the left coronary artery originating anomalously from the pulmonary artery, such as the Bland-Garland-White syndrome (Bland, White, and Garland, 1933), or of the right coronary artery originating from the pulmonary artery (Tingelstad, Lower, and Eldredge, 1972; Wald et al., 1971) have been reported. With the advent of coronary arteriography many other coronary anomalies (Ogden, 1970; Pachinger, Vanden Hoven, and Judkins, 1974) as well as fistulae between coronary arteries and heart chambers have been described (McNamara and Gross, 1969; Morgan et al., 1972; Reddy, Gupta, and Hamby, 1974; De Nef, 1971).

We present here a rare anomaly which might be considered a variant of the Bland-Garland-White syndrome and which has not, to our knowledge, been reported previously.

\section{Case report}

A 35-year-old white woman was admitted to the cardiological clinic because of anginal symptoms for the past 17 years. On one occasion she had been told that she had a ventricular septal defect, because of a cardiac murmur. Several months before admission she had had atypical chest pain and dyspnoea on exertion. Interestingly, the chest discomfort occurred when entering a heated room from the cold open air.

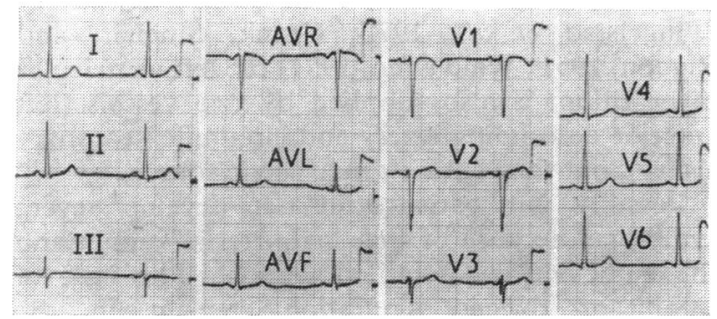

FIG. 1. Electrocardiogram at rest.
On examination the pulse rate was $90 / \mathrm{min}$ regular; blood pressure $110 / 80 \mathrm{mmHg}(14.6 / 10.6 \mathrm{kPa})$; a systolic murmur could be heard over the base, without transmission, and a high frequency diastolic murmur over the apex. A third and fourth heart sound were present. Routine blood tests were within normal limits. The electrocardiogram (Fig. 1) showed no $R$ wave progression from V1 to V3; chest $x$-ray examination was normal. The exercise tolerance on bicycle ergometry was reduced; the test was discontinued at 75 Watts because of dyspnoea, but no anginal symptoms were present at this level. Nevertheless, a significant ST segment depression suggestive of myocardial ischaemia was noted in leads I, II, and V3 to V6. Left and right heart catheterization showed a pulmonary artery pressure of

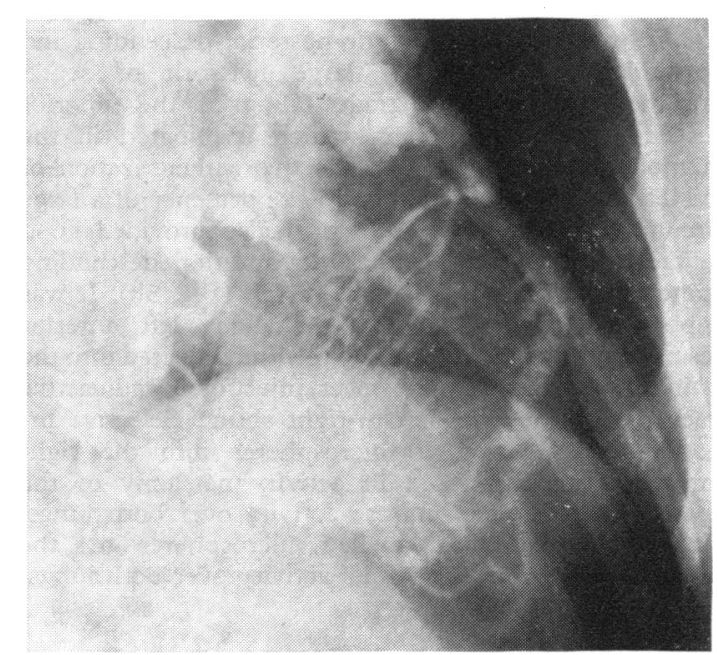

F I G. 2 Selective angiogram of right coronary artery. The distat right coronary system provides good collateral circulation to anterior descending branch which empties into pulmonary artery. 


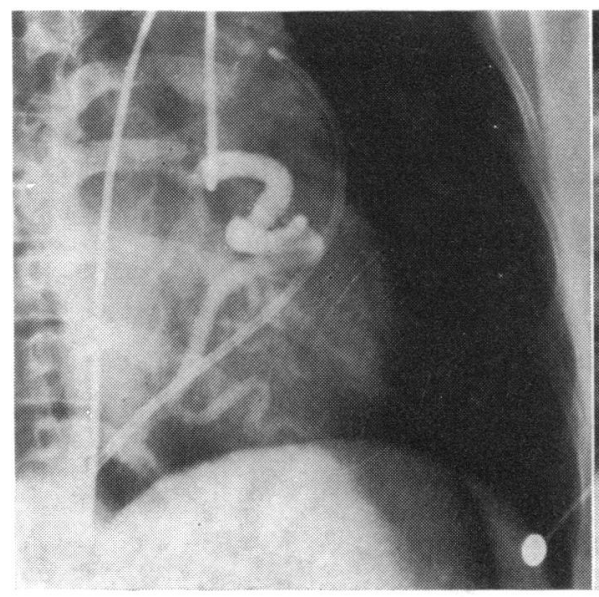

(a)

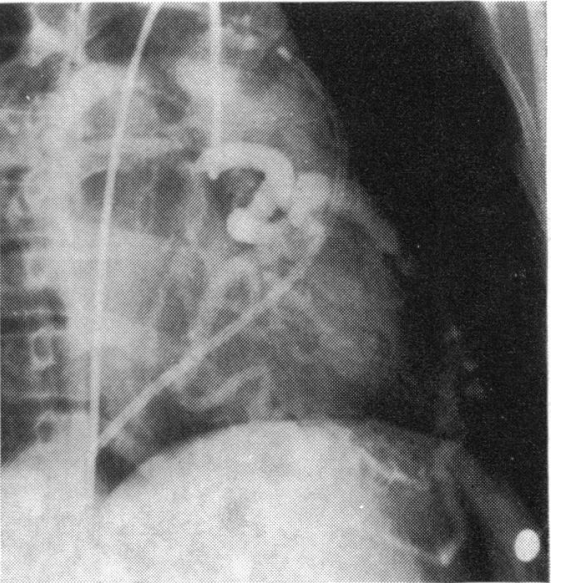

(b)

FIG. 3 (a) Selective catheterization of left coronary ostium shows large circumflex artery.

(b) Circumflex artery provides rich collateral network to anomalous anterior descending branch.

$30 / 12 / 20 \mathrm{mmHg}(4 \cdot 0 / 1 \cdot 6 / 2 \cdot 7 \mathrm{kPa})$; the end-diastolic pressure in the left ventricle was $15 \mathrm{mmHg}(2 \mathrm{kPa})$; $\mathrm{dP} / \mathrm{dt} \max 2040 \mathrm{mmHg} / \mathrm{s}(271 \mathrm{kPa})$, cardiac index $4.4 \mathrm{l} / \mathrm{min}$ per $\mathrm{m}^{2}$ (AV difference $3.8 \mathrm{vol} \%$ ). No oxygen saturation step-up in the pulmonary artery was found despite many measurements. Left ventriculography showed a normally contracting left ventricle; the ejection fraction was calculated at 70 per cent.

Coronary arteriography, performed by the Judkins technique, showed a right coronary artery arising from a normally situated ostium in the right sinus of Valsalva. The large and tortuous right coronary main stem followed the usual course in the atrioventricular groove and bifurcated at the crux into posterior descending and posterolateral systems. A large network of septal branches provided retrograde filling of the anterior descending coronary artery which terminated in the pulmonary artery (Fig. 2). Selective catheterization of the left coronary ostium showed the presence of a large circumflex artery (Fig. 3a) which also provided good collateral circulation to the left anterior descending branch via epicardial collateral vessels (Fig. 3b). It was impossible to visualize the anomalous left anterior descending artery with contrast medium injected into the main pulmonary trunk. However, injection of radioactive tracers confirmed the left-to-right shunt. Selective injection of ${ }^{181} \mathrm{~J}$-labelled microspheres into the right coronary artery resulted in activity not only of the inferior wall but also intense activity over both lungs. The injection of ${ }^{99} \mathrm{Tc}$-labelled microspheres into the circumflex artery also revealed activity over both lungs.

\section{Discussion}

The coronary circulatory pattern in this case is a variant of the Bland-Garland-White syndrome. The anomalous origin of the left coronary artery from the pulmonary artery has been reviewed in a large series by Wesselhoeft (Wesselhoeft, Fawcett, and Johnson, 1968). The authors showed that in most cases the patient does not live more than 2 years. Therefore cases have been classified as infantile and post-infantile (Flamm et al., 1968). The anomaly may be asymptomatic or anginal symptoms or signs of cardiac failure may develop. Mitral regurgitation is common and may be the main presenting sign (Burchell and Brown, 1962). The typical electrocardiographic features are left axis deviation, signs of left ventricular hypertrophy, evidence of myocardial infarction, or at least small q waves in leads I and aVL (Wesselhoeft et al., 1968; Perry and Scott, 1970). None of these findings was present in our case. The only abnormality was the ST segment depression during bicycle ergometry.

The significant difference in coronary arterial anatomy between the classical Bland-GarlandWhite syndrome and the variation in our case is the presence of a dual coronary arterial supply (right coronary artery and circumflex artery) with two aortic sources. In cases of anomalous origin of the right coronary artery from the pulmonary artery (Tingelstad et al., 1972; Cronk, Sinclair, and Rigdon, 1951; Wald et al., 1971) the left ventricular myocardium is also supplied by two vessels (left anterior descending artery and circumflex coronary artery), but they have a single aortic source.

Possibly our patient did not develop severe symptoms because of the dual arterial supply and the sufficient collateral circulation. The lack of significant oxygen saturation step-up in the pulmonary artery is common with an anomalous left coronary artery (Wesselhoeft $e t$ al., 1968; Perry 
and Scott, 1970). Perry reported a better prognosis in children who develop a significant left-to-right shunt, detectable by oxygen saturation within the pulmonary artery. In our patient the left-to-right shunt was demonstrated by radioactive tracers. Angiographic visualization of the anomalous left anterior descending branch by injecting contrast medium into the pulmonary artery could be obtained only rarely. Success seems to depend on an antegrade flow from the pulmonary artery to the aberrant vessel (Bookstein, 1964; Goldberger, 1960).

Surgical intervention has become feasible with the advent of bypass surgery and has been successful in patients with an anomalous origin of a left or right coronary artery from the pulmonary artery (Gasior et al., 1971; Chaitman et al., 1975; El-Said et al., 1973; Tingelstad et al., 1972; Barrand et al. 1975). The likelihood of sudden death has been the main indication for surgery in these patients (Wesselhoeft et al., 1968; Wüthrich, 1951; Flamm et al., 1968; Wright et al., 1970). We did not consider surgery for our patient because of the absence of disabling angina pectoris and the presence of a dual coronary arterial supply providing excellent collateral circulation to the anomalous vessel.

\section{References}

Barrand, K. G., Brooks, I. A. B., Webb-Peploe, M. M., and Braimbridge, M. V. (1975). Anomalous origin of the left coronary artery from pulmonary artery: surgical consideration in the adult. British Heart fournal, 37, 441.

Bland, E. F., White, P. D., and Garland, J. (1933). Congenital anomalies of the coronary arteries: report of an unusual case associated with cardiac hypertrophy. American Heart fournal, 8, 787.

Bookstein, J. J. (1964). Aberrant left coronary artery. American Fournal of Roentgenology, 91, 515.

Burchell, H. B., and Brown, A. L. (1962). Anomalous origin of coronary artery from pulmonary artery masquerading as mitral insufficiency. American Heart fournal, 63, 388.

Chaitman, B. R., Bourassa, M. G., Lespérance, J., and Grondin, P. (1975). Anomalous left coronary artery from pulmonary artery. Circulation, 51, 552.

Cronk, E. S., Sinclair, J. G., and Rigdon, R. H. (1951). An anomalous coronary artery arising from the pulmonary artery. American Heart fournal, 42, 906.

De Nef, J. J. F. (1971). Congenital coronary artery fistula: report of 17 cases with a note on natural history of lesion. British Heart Fournal, 33, 150.

El-Said, G. M., Ruzyllo, W., Williams, R. L., Mullins, C. E., Hallmann, G. L., Cooley, D. A., and McNamara, D. G. (1973). Early and late result of saphenous vein graft for anomalous origin of left coronary artery from pulmonary artery. Circulation, 47, Suppl. 3, 2.
Flamm, M. D., Stinson, E. B., Hultgren, H. N., Shumway, N. E., and Hancock, E. W. (1968). Anomalous origin of the left coronary artery from the pulmonary artery. Circulation, 38, 113.

Gasior, R. M., Winters, W. L., Glick, H., Sandiford, F. Chapman, D. W., and Morris, G. C., Jr. (1971). Anomalous origin of left coronary artery from pulmonary artery. American fournal of Cardiology, 27, 215.

Goldberger, E. (1960). Angiocardiographic diagnosis of an anomalous left coronary artery originating from the pulmonary artery. American fournal of Cardiology, 6, 694.

McNamara, J. J., and Gross, R. E. (1969). Congenital coronary artery fistula. Surgery, 65, 59.

Menke, J. A., Shaher, R. M., and Wolff, G. S. (1972). Ejection fraction in anomalous origin of the left coronary artery from the pulmonary artery. American Heart fournal, 84, 325.

Morgan, J. R., Forker, A. D., O'Sullivan, M. J., and Fosburg, R. G. (1972). Coronary arterial fistulas: seven cases with unusual features. American fournal of Cardiology, 30, 432.

Ogden, J. A. (1970). Congenital anomalies of the coronary arteries. American fournal of Cardiology, 25, 474.

Pachinger, O., Vanden Hoven, P., and Judkins, M. P. (1974). Single coronary artery - a cause of angina pectoris. European fournal of Cardiology, 2, 161.

Perry, L. W., and Scott, L. P. (1970). Anomalous left coronary artery from pulmonary artery. Report of 11 cases; review of indications for and results of surgery. Circulation, 41, 1043.

Reddy, K., Gupta, M., and Hamby, R. I. (1974). Multiple coronary arteriosystemic fistulas. American fournal of Cardiology, 33, 304.

Tingelstad, J. B., Lower, R. R., and Eldredge, W. J. (1972). Anomalous origin of the right coronary artery from the main pulmonary artery. Fournal of Cardiology, 30, 670.

Van der Hauwaert, L. G., Stalpaert, G. L., and Verhaeghe, L. (1965), Anomalous origin of the left coronary artery from the pulmonary artery: a therapeutic problem. American Heart fournal, 69, 538.

Wald, S., Stonecipher, K., Baldwin, B. J., and Nutter, D. O. (1971). Anomalous origin of the right coronary artery from the pulmonary artery. American fournal of Cardiology, 27, 676.

Wesselhoeft, H., Fawcett, J. S., and Johnson, A. L. (1968). Anomalous origin of the left coronary artery from the pulmonary artery trunk: its clinical spectrum, pathology, and pathophysiology based on a review of 140 cases with seven further cases. Circulation, 38, 403.

Wright, N. L., Baue, A. G., Baum, S., Blakemore, W. S., and Zinsser, H. F. (1970). Coronary artery steal due to an anomalous left coronary artery originating from the pulmonary artery. Fournal of Thoracic and Cardiovascular Surgery, 58, 461.

Wüthrich, R. (1951). Uber den Abgang der Arteria coronaria sinistra aus der Arteria Pulmonalis. Zugleich ein Beitrag zum Problem des plötzlichen Todes. Cardiologia, 18, 193.

Requests for reprints to Dr. P. Probst, Kardiologische Universitäts-Klinik, Garnisongasse 13, A-1090 Vienna, Austria. 